\title{
Improving Effects of Stored Wheat Flour on Pancake Texture
}

\author{
Chieko NAKAmura $^{1}$ and Masaharu Seguchi ${ }^{2}$ \\ ${ }^{1}$ Depart of Food and Nutritional Science, Kobe Women's Junior College, Chuo-ku, Kobe City, 650-0046, Japan \\ ${ }^{2}$ Laboratory of Food Technology, Faculty of Home Economics, Kobe Women's University, Suma-Ku, Kobe City, 654-8585, Japan
}

Received June 21, 2006; Accepted April 9, 2007

\begin{abstract}
Various protein containing soft wheat flours were stored at room temperature $\left(15-25^{\circ} \mathrm{C}\right)$ for 12 months. Pancakes baked using these flours yielded higher pancake springiness when tested. The wheat flours were fractionated to water solubles, gluten, prime starch and tailings fractions by an acetic acid fractionation technique. A gradual increase in the interaction between prime starch and tailings fractions was observed after inclusion of these fractions in each flour. However, the stored time for complete interaction varied in relation to flour protein content. It was found that the increase of pancake springiness was strongly associated with the interaction between prime starch and tailings fractions in stored wheat flour. Mixograph profiles showed a gradual increase in the hydrophobicity of wheat flour with increased storage. Rapid Visco Analyser (RVA) profiles of these flours indicated that the maximum viscosity increased and pasting temperature decreased; these effects were probably attributable to the hydrophobic interaction of flour fractions.
\end{abstract}

Keywords: stored wheat flour, pancake springiness, interaction of wheat flour components

\section{Introduction}

As pancakes are baked using only wheat flour (100\%), sugar $(26.4 \%)$, leavening agent $(1.4 \%)$, acid reagent $(2.1 \%)$ and water $(91 \%)$, the cake is leavened by gas trapped by flour protein. Other cakes, such as Kasutera, which is composed of wheat flour (100\%), sugar (176\%), whole egg (184\%), egg yolk $(32 \%)$, liquid sugar $(52 \%)$, honey $(24 \%)$ and water $(40 \%)$, are leavened by air trapped by egg white protein film. Therefore, the role of wheat flour in such cakes is different. It is also known that storage of wheat flour is essential in improving the springiness and palatability of cakes such as pancakes and Kasutera cake; thus, the effect of stored wheat flour on cakes would differ from that of unstored flour.

Seguchi (1990), Seguchi et al. (1998), and Ozawa and Seguchi (2006) reported that dry heated $\left(120^{\circ} \mathrm{C}\right)$ and stored (room temperature $100^{\circ} \mathrm{C}$ ) wheat flour improved pancake springiness, and the improvements could be due to the interaction between prime starch and tailings fractions in these flours. Furthermore, Seguchi (1993) suggested that the physical interaction between prime starch and tailings fractions are caused by changes in starch granule surface proteins from hydrophilic to hydrophobic during storage. It has been shown that heating of wheat flour affects the texture of foods made with wheat flour (Hamer and Hoseney, 1998). Heating wheat flour between 60 and $100^{\circ} \mathrm{C}$ is also reported to be detrimental to loaf volume (Becker and Sallans, 1956).

In the present study, in order to clarify the mechanism of the effect of storage on pancake flour, various protein-

* To whom correspondence should be addressed.

E-mail: seguchi@suma.kobe-wu.ac.jp containing soft wheat flours were stored at room temperature for 12 months, after which time pancake baking tests were performed. The wheat flours were further fractionated to water solubles, gluten, tailings and prime starch fractions by acetic acid fractionation $(\mathrm{pH} 3.5)$, and we investigated whether interaction between prime starch and tailings fractions had occurred. We determined the hydrophobicity of stored flour through analysis of the rheological changes in these flours by mixograph and Rapid Visco Analyser (RVA) tests.

\section{Materials and Methods}

Wheat flour Wheat flours "Takaragasa gold", "Furian", "Tokutakaragasa”, and "Aokoma” were donated by Masuda Flour Milling Co., Ltd., Kobe, Japan. These flours are usually mill-mixed in a single day. Protein conversion was $\mathrm{N} \times 5.7$ (AACC method 46-10, 2000), and ash was determined according to the AACC method $(08-01,2000)$ at $14.2 \%$ moisture. General analysis of the flours is shown in Table 1.

Storage of wheat flour Wheat flour $(1 \mathrm{~kg})$ was put into an iron plate $(25 \times 34$; height, $3 \mathrm{~cm})$ in order to circulate air for drying, and stored at room temperature $\left(15-25^{\circ} \mathrm{C}\right)$ for 2, 4, 6, 8, 10 and 12 months. Storage of wheat flours "Takaragasa gold", "Furian”, "Tokutakaragasa”, and “Aokoma" was started on the same day. Samples were not protected from moisture loss, and moisture contents changed during storage. After the designated storage period, samples were kept at $-20^{\circ} \mathrm{C}$.

Pancake baking The pancake baking test was performed according to the method of Seguchi and Matsuki (1977). Wheat flour (moisture content 14\%; $110 \mathrm{~g}$ ), sugar $(29 \mathrm{~g})$, Na-acid pyrophosphate $(2.3 \mathrm{~g})$ and $\mathrm{NaHCO}_{3}(1.55 \mathrm{~g})$ 
were mixed. The dry mix and $100 \mathrm{~mL}$ water were homogenized for 30 seconds in a Kitchen Aid mixer (Kenmix Chef; Aicoh Mixers \& Aicoh Systems Co., Ltd., Toda, Japan) at a low speed. Moisture content (\%) of flour sample was measured and then dry weight of flour and total added water (moisture from flour plus $100 \mathrm{~mL}$ ) were adjusted to $94.6 \mathrm{~g}$ and $125.4 \mathrm{~mL}$, respectively. Batter (220 g) was transferred to an iron dish (diameter, $15 \mathrm{~cm}$; depth, $2.5 \mathrm{~cm}$ ) and baked in a $210^{\circ} \mathrm{C}$ oven (Sanyo Drying Oven MOV-212; Sanyo Co., Ltd., Oosaka, Japan) for $10 \mathrm{~min}$, and baked for a further 3 min after turning. Pancake volume $\left(\mathrm{cm}^{3}\right)$ was measured by the rapeseed displacement method (Seguchi and Matsuki, 1977). Pancake springiness (resistance to crushing) was measured as follows; pancake volume (V1) and weight (g) were measured after just 1 min of baking, and the pancake was pressed for 30 seconds by a plunger ( $5 \mathrm{~cm}$ diameter) with a $5.19-\mathrm{kg}$ weight after $5 \mathrm{~min}$ of baking, which was equivalent to $29.38 \mathrm{~g} / \mathrm{cm}^{2}$ of pancake surface. After release of the pressure, the pancake volume was measured (V2), and pancake springiness was calculated as SV2/SV1 $\times 100 \%$ (SV, specific volume $\left(\mathrm{cm}^{3} / \mathrm{g}\right)$ ).

Fractionation of Wheat Flour with Acetic Acid Wheat flour was fractionated using the method of Seguchi et al., (1998). The homogenization step was performed using an automated mortar and pestle (mortar, 120 rpms; pestle, 70 rpms) (ANM-150 T; Nittokagaku Co. Ltd, Nagoya, Japan) (Seguchi et al. 1998). Flour (50 g) was mixed with $150 \mathrm{~mL}$ of water and homogenized for $20 \mathrm{~min}$ at room temperature. After centrifugation at $1700 \times g$ for $20 \mathrm{~min}$ at room temperature, the supernatant was freeze-dried to recover the water soluble fraction. The pellet was homogenized in $125 \mathrm{~mL}$ of $0.136 \mathrm{~N}$ acetic acid solution for $20 \mathrm{~min}$ and the homogenate was centrifuged. The resulting pellet $(\mathrm{pH}$ 3.5) was further homogenized in $75 \mathrm{~mL}$ of $0.0283 \mathrm{~N}$ acetic acid solution and centrifuged. Supernatants recovered from both centrifugations were combined and freezedried to recover the gluten fraction. The resulting pellet (pH 3.5) was homogenized in $150 \mathrm{~mL}$ of water and the $\mathrm{pH}$ was adjusted to 5.0 with $5 \mathrm{~N} \mathrm{NaOH}$ solution. After centrifugation, two layers appeared; an upper yellowish and viscous layer (tailings fraction) and a lower white layer (prime starch fraction). These fractions were collected separately with a spatula and air-dried.

RVA (Rapid visco analyser) test Samples of $4 \mathrm{~g}$ wheat flour (moisture content 14\%) and $25.0 \mathrm{~mL}$ water were mixed and tested in a Rapid Visco Analyser-4 (New Scientific Pty. Ltd., Warriewood, Australia). After determination of wheat flour moisture content, sample weight and added water were calculated based on the dry weight (3.44 g) and water $(25.6 \mathrm{~mL})$ of each sample. Test time was 13 min. Initial idle temperature was $50^{\circ} \mathrm{C}$. The suspension was heated from $50(1 \mathrm{~min} 00 \mathrm{sec})$ to $95^{\circ} \mathrm{C}(4 \mathrm{~min} 42 \mathrm{sec})$ and held at $95^{\circ} \mathrm{C}$ until $11 \mathrm{~min} 00 \mathrm{sec}$.

10-g mixograph test Samples of $10.0 \mathrm{~g}$ wheat flour (moisture content, 14\%) and $5.0 \mathrm{~mL}$ water were mixed and tested in a 10-g mixograph (National MFG. Company, Lincoln, NE, USA). After determination of moisture content of wheat flour, sample weight and added water were calculated based on the dry weight $(8.60 \mathrm{~g})$ and water $(6.40$
Table 1. Acetic acid fractionation of wheat flour (Takaragasa gold, Furian, Tokutakaragasa, and Aokoma).

\begin{tabular}{lcccc}
\hline & $\begin{array}{c}\text { Recovery } \\
(\%)\end{array}$ & $\begin{array}{c}\text { Protein } \\
(\%)\end{array}$ & $\begin{array}{c}\text { Ash } \\
(\%)\end{array}$ & $\begin{array}{c}\text { Moisture content } \\
(\%)\end{array}$ \\
\hline Takaragasa gold & 100 & $9.06 \pm 0.01$ & $0.42 \pm 0.02$ & 11.8 \\
Water Solubles & 4.0 & - & - & - \\
Gluten & 5.0 & $81.52 \pm 0.40$ & $0.81 \pm 0.00$ & 7.2 \\
Prime Starch & 44.5 & $0.82 \pm 0.00$ & $0.17 \pm 0.00$ & 7.0 \\
Tailings & 41.0 & $8.40 \pm 0.04$ & $0.26 \pm 0.03$ & 6.9 \\
\hline Furian & 100 & $9.30 \pm 0.00$ & $0.39 \pm 0.01$ & 13.3 \\
Water Solubles & 5.0 & - & - & - \\
Gluten & 6.5 & $68.97 \pm 0.73$ & $0.60 \pm 0.00$ & 6.4 \\
Prime Starch & 41.0 & $0.94 \pm 0.01$ & $0.17 \pm 0.02$ & 6.1 \\
Tailings & 43.0 & $4.11 \pm 0.46$ & $0.21 \pm 0.02$ & 6.9 \\
\hline Tokutakaragasa & 100 & $9.69 \pm 0.06$ & $0.43 \pm 0.01$ & 12.9 \\
Water Solubles & 5.0 & - & - & - \\
Gluten & 6.0 & $83.27 \pm 0.23$ & $0.55 \pm 0.03$ & 7.0 \\
Prime Starch & 33.5 & $0.94 \pm 0.02$ & $0.17 \pm 0.00$ & 7.5 \\
Tailings & 50.0 & $4.73 \pm 0.03$ & $0.20 \pm 0.00$ & 8.6 \\
\hline Aokoma & 100 & $10.17 \pm 0.10$ & $0.45 \pm 0.01$ & 12.9 \\
Water Solubles & 5.5 & - & - & - \\
Gluten & 5.0 & $81.24 \pm 3.50$ & $0.52 \pm 0.08$ & 7.1 \\
Prime Starch & 15.0 & $1.13 \pm 0.32$ & $0.15 \pm 0.01$ & 7.6 \\
\hline Tailings & 69.5 & $3.17 \pm 0.07$ & $0.18 \pm 0.01$ & 8.2 \\
\hline & & & & \\
\hline
\end{tabular}

$\mathrm{mL}$ ) of each sample. Mixing speed of the mixograph was $86 \mathrm{rpm}$.

Statistical Analysis A statistical software package (SPSS Inc., Chicago, IL, USA) was used for the statistical analyses. Two pancakes were baked for each treatment and specific volume $\left(\mathrm{cm}^{3} / \mathrm{g}\right)$ was measured 2 times for each sample and averaged. Analysis produced significant $\mathrm{F}$ values by analysis of variance (ANOVA) followed by Duncan's multiple range test for comparison of mean.

\section{Results and Discussion}

Pancake baking test and acetic acid fractionation of wheat flour The results of pancake baking tests and acetic acid fractionation of "Takaragasa gold" flour, which had the lowest protein content $(9.06 \%)$, are shown in Tables 1 and 2, and Fig. 1-A. SV1 indicates the pancake specific volume before and SV2 indicates the specific volume after pressing with a 5.19-kg weight (Table 2). Although SV1 gradually decreased with increasing storage time due to the denaturation of wheat proteins, SV2 was increased. Springiness, which was calculated as SV 2/SV1 x 100\%, increased with stored time, and 90\% springiness could be obtained after 10 months of storage (Table 2). The results of acetic acid fractionation of unstored flour indicated that the recovery of water solubles $(4 \%)$ and gluten (5\%) fractions was almost constant for 12 months (Fig. 1-A). However, the tailings and prime starch fractions, which were 41.0 and $44.5 \%$ in unstored flour (Table 1), changed to 68.0 and $19.0 \%$ after 10 months, respectively, indicating that a greater percentage of tailings fraction resulted as time progressed. Thus, less prime starch fractionation $(\mathrm{w} / \mathrm{w})$ occurred during storage, 
Table 2. Results of Pancake Baking Tests.

\begin{tabular}{|c|c|c|c|c|c|c|}
\hline \multicolumn{4}{|c|}{ Takaragasa gold } & \multicolumn{3}{|c|}{ Furian } \\
\hline Month & $\begin{array}{c}\text { Specific volume (SV1) } \\
(\mathrm{cm} / \mathrm{g})\end{array}$ & $\begin{array}{c}\text { Specific volume (SV2) } \\
\left(\mathrm{cm}^{\prime} / \mathrm{g}\right)\end{array}$ & $\begin{array}{c}\text { Springiness } \\
(\%)\end{array}$ & $\begin{array}{c}\text { Specific volume (SV1) } \\
(\mathrm{cm} / \mathrm{g})\end{array}$ & $\begin{array}{c}\text { Specific volume (SV2) } \\
\left(\mathrm{cm}^{\prime} / \mathrm{g}\right)\end{array}$ & $\begin{array}{c}\text { Springiness } \\
(96)\end{array}$ \\
\hline 0 & $2.35 a(0.01)$ & $1.62 \mathrm{a}(0.01)$ & $69.15 \mathrm{a}(0.78)$ & $2.39 \mathrm{a}(0.01)$ & $1.65 a(0.01)$ & $69.00 \mathrm{a}(0.42)$ \\
\hline 2 & $2.27 \mathrm{~b}(0.01)$ & $1.59 \mathrm{a}(0.04)$ & $70.10 \mathrm{a}(2.12)$ & $2.32 \mathrm{~b}(0.01)$ & $1.59 \mathrm{~b}(0.02)$ & $68.60 \mathrm{a}(0.85)$ \\
\hline 4 & $2.20 \mathrm{c}(0.01)$ & $1.61 \mathrm{a}(0.01)$ & $72.55 \mathrm{~b}(0.64)$ & $2.26 \mathrm{c}(0.01)$ & $1.62 a(0.01)$ & $71.35 \mathrm{a}(0.50)$ \\
\hline 6 & $2.14 d(0.01)$ & $1.66 \mathrm{a}(0.00)$ & $77.75 \mathrm{c}(0.35)$ & $2.24 d(0.01)$ & $1.65 \mathrm{a}(0.03)$ & $73.906(1.91)$ \\
\hline 8 & $2.13 e(0.03)$ & $1.67 \mathrm{~b}(0.02)$ & $78.20 \mathrm{~d}(0.14)$ & $2.16 \mathrm{e}(0.06)$ & $1.82 \mathrm{c}(0.01)$ & $84.10 \mathrm{c}(2.69)$ \\
\hline 10 & $2.03 f(0.04)$ & $1.82 \mathrm{c}(0.01)$ & $89.75 \mathrm{e}(1.20)$ & $2.22 \mathrm{f}(0.02)$ & $1.91 \mathrm{~d}(0.03)$ & $86.35 \mathrm{~d}(2.05)$ \\
\hline 12 & $2.09_{\mathrm{B}}(0.01)$ & $1.80 d(0.01)$ & $86.00 \mathrm{f}(0.78)$ & $2.06 \mathrm{~g}(0.01)$ & $1.92 \mathrm{e}(0.02)$ & $93.20 \mathrm{e}(1.27)$ \\
\hline \multicolumn{4}{|c|}{ Tokutakaragasa } & \multicolumn{3}{|c|}{ Aokoma } \\
\hline Month & $\begin{array}{c}\text { Specific volume (SV1) } \\
\left(\mathrm{cm}^{2} / \mathrm{g}\right)\end{array}$ & $\begin{array}{c}\text { Specific volume (SV2) } \\
\left(\mathrm{cm}^{\prime} / \mathrm{g}\right)\end{array}$ & $\begin{array}{c}\text { Springiness } \\
(\%)\end{array}$ & $\begin{array}{c}\text { Specific volume (SV1) } \\
(\mathrm{cm} / \mathrm{g})\end{array}$ & $\begin{array}{c}\text { Specific volume (SV2) } \\
(\mathrm{cm} / \mathrm{g})\end{array}$ & $\begin{array}{c}\text { Springiness } \\
(\%)\end{array}$ \\
\hline 0 & $2.30 \mathrm{a}(0.06)$ & $1.65 \mathrm{a}(0.02)$ & $71.45 \mathrm{a}(0.64)$ & $2.19 \mathrm{a}(0.04)$ & $1.61 \mathrm{a}(0.04)$ & $73.46 \mathrm{a}(0.04)$ \\
\hline 2 & $2.30 \mathrm{a}(0.03)$ & $1.62 \mathrm{a}(0.03)$ & $70.55 a(0.50)$ & $2.21 \mathrm{a}(0.01)$ & $1.66 \mathrm{a}(0.04)$ & $75.08 \mathrm{a}(1.38)$ \\
\hline 4 & $2.22 \mathrm{a}(0.01)$ & $1.65 a(0.00)$ & $73.95 a(0.78)$ & $2.20 \mathrm{a}(0.01)$ & $1.64 a(0.01)$ & $74.47 a(0.11)$ \\
\hline 6 & $2.28 \mathrm{a}(0.04)$ & $1.61 \mathrm{a}(0.02)$ & $70.35 a(0.07)$ & $2.15 \mathrm{a}(0.06)$ & $1.676(0.02)$ & $77.34 \mathrm{~b}(0.92)$ \\
\hline 8 & $2.22 \mathrm{a}(0.04)$ & $1.72 \mathrm{~b}(0.02)$ & $77.55 \mathrm{~b}(0.50)$ & $1.976(0.01)$ & $1.75 c(0.01)$ & $88.90 c(1.41)$ \\
\hline 10 & $2.12 \mathrm{~b}(0.03)$ & $1.83 c(0.03)$ & $86.25 c(2.47)$ & $1.83 \mathrm{c}(0.01)$ & $1.72 \mathrm{~d}(0.02)$ & $93.80 \mathrm{~d}(0.57)$ \\
\hline 12 & $2.13 c(0.04)$ & $1.78 d(0.05)$ & $83.60 \mathrm{~d}(1.13)$ & $1.76 \mathrm{~d}(0.01)$ & $1.64 a(0.00)$ & $93.50 \mathrm{e}(0.57)$ \\
\hline
\end{tabular}

Values represent means of two repricates and standard deviation an parenthesis.

Means followed by the different letters in rows are significantly different at $p=0.05$ according to Duncan's multiple range test.

and was subsequently separated by centrifugation (Fig. 1A). However, the binding of prime starch and tailings fractions was not complete after 12 months; longer storage is required for complete binding.

Next, "Furian" flour, with a protein content of 9.30\%, was examined using the same procedure (Tables 1 and 2, and Fig. 1-B). The springiness of pancakes baked with this flour reached $93 \%$ after 12 months of storage (Table 2). The acetic acid fractionation of unstored "Furian" flour indicated that water solubles, gluten, tailings, and prime starch fractions were 5.0, 6.5, 43.0, and $41.0 \%$, respectively (Table 1). After 12 months, recovery of the water solubles and gluten fractions was unchanged (Fig. 1-B). However, the tailings fraction increased to $79.0 \%$ and the prime starch fraction decreased to $5.0 \%$, indicating that the prime starch fraction was included in tailings fraction due to interactions between them (Fig. 1-B). The rate of the interaction between prime starch and tailings fractions was larger than that of "Takaragasa gold" flour.

The data for "Tokutakaragasa" flour, with a protein content of 9.69\%, can be seen in Tables 1 and 2, and Fig. 1-C; the results of pancake baking are shown in Table 2. Pancake springiness increased to $86 \%$ after 10 months of storage (Table 2). Acetic acid fractionation of unstored flour indicated that the water solubles, gluten, tailings and prime starch fractions were 5.0, 6.0, 50.0, and 33.5\%, respectively (Table 1). The first two fractions were almost unchanged after 10 months, but interaction between prime starch and tailings fractions occurred after 2 months. Furthermore, tailings fraction increased to $80 \%$ and the prime starch fraction decreased to $4.05 \%$ after 12 months, again indicating an interaction between prime starch and tailings fractions during storage (Fig. 1-C).

Data for "Aokoma", the flour with highest protein content $(10.17 \%)$, can be seen in Tables 1 and 2, and Fig. 1-D. Although SV1 of unstored flour was lowest of all flours, it gradually increased over 4 months of storage, probably due to the denaturation of wheat proteins. Springiness of pancakes made from this flour increased with storage (Table 2). The results of acetic acid fractionation of the unstored flour indicated that the water solubles, gluten, tailings, and prime starch fractions were 5.5, 5.0, 69.5, and
$15.0 \%$, respectively (Table 1 ). The recovery $(\%)$ of the water solubles and gluten fractions were unchanged after 12 months. However, tailings fraction increased to $83.0 \%$, and prime starch fraction decreased to $0.0 \%$ after 12 months (Fig. 1-D), indicating that the two fractions were not separated and showed strong interaction. Recovery of the prime starch fraction of unstored "Aokoma" flour was considerably lower and the tailings fraction considerably higher than the other unstored flours, indicating that these two fractions interacted each other even in unstored flours.

The results in Figs. 1-A-D suggest that the interaction between prime starch and tailings fraction occurred early in the storage period, and in the following order: Takaragasa gold $(\mathrm{A})<$ Furian $(\mathrm{B})<$ Tokutakaragasa $(\mathrm{C})<$ Aokoma (D). This corresponds to the order of flour protein content (Table 1). Kusunose et al. (2002) reported the same result for 8 varieties of protein-containing wheat flours stored at $60^{\circ} \mathrm{C}$, and reported that some wheat proteins are interact with prime starch and tailings fractions in stored wheat flour by acting as a binder between them.

From the results of pancake baking tests and acetic acid fractionation of these protein-containing flours, it was suggested that storage of each wheat flour at room temperature would result in high pancake springiness and induce interaction between the prime starch and tailings fractions.

The correlation coefficients ( $r$ ) between pancake springiness and recovery (\%) of prime starch and tailings fraction of each wheat flour were calculated (Table 3). For all flours, $r$ values between springiness and prime starch fractions were $-0.8 \sim-0.9$, and those for tailings fractions were $+0.8 \sim+0.9$, indicating that the interaction between tailings and prime starch fractions was highly related to the increase of pancake springiness. Seguchi et al. (1984) also showed the same results in a strain of Alps wheat flour. Seguchi (1993) indicated that prime starch fraction in wheat flour stored at room temperature for 233 days showed strong hydrophobicity due to changes in starch granule surface proteins, and the amount of starchgranule surface proteins from aged flours was three to four times greater than the control samples. However, 

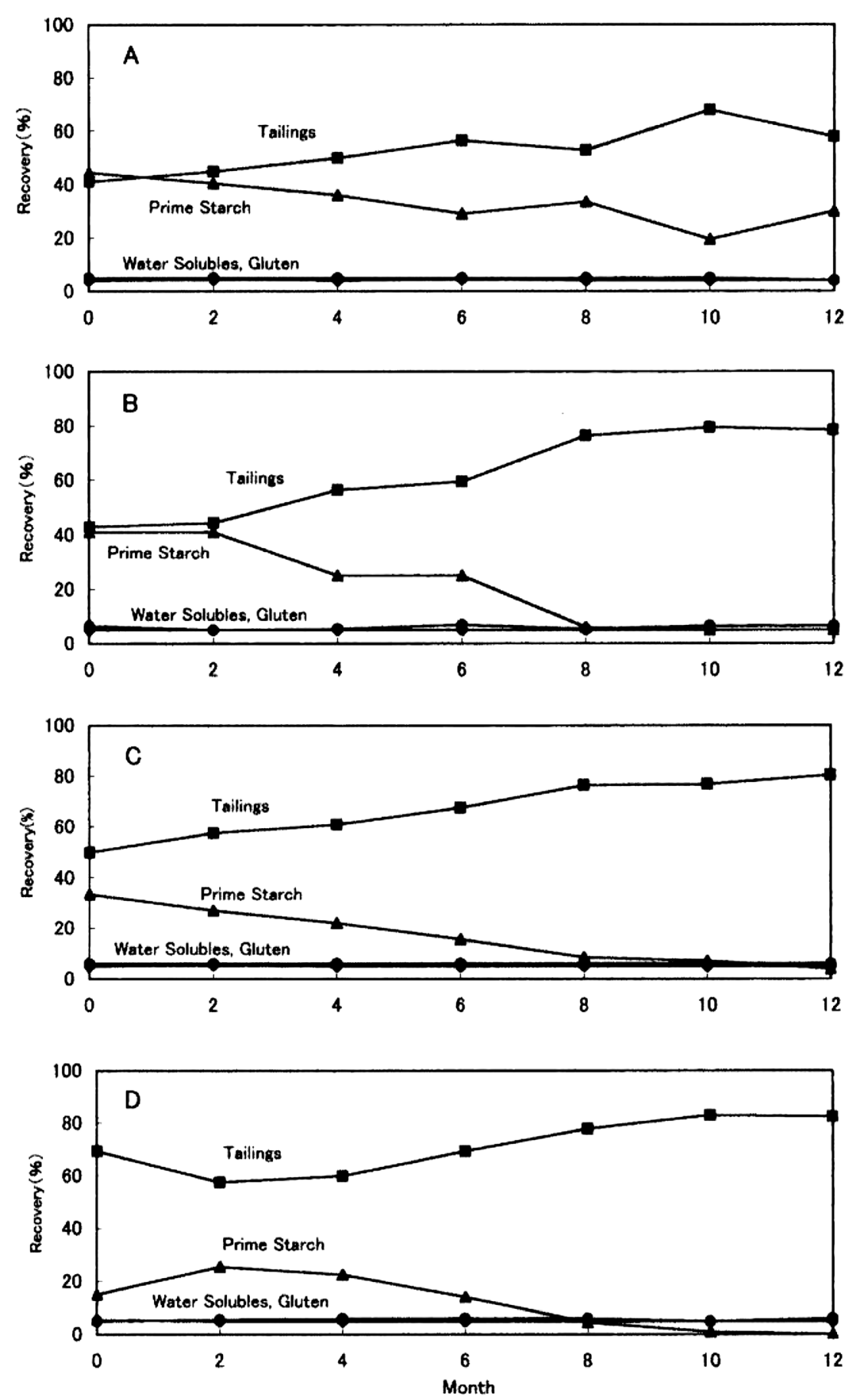

Fig. 1. Results of pancake baking tests and acetic acid fractionations of "Takaragasa gold"(A), "Furian"(B), "Tokutakaragasa"(C) and "Aokoma" (D) flours stored at room temperature for 12 months.

Table 3. Correlation coefficients (r) between pancake springiness and Prime starch (PS), and Tailings (T) fraction, respectively.

\begin{tabular}{lcc}
\hline \multicolumn{1}{c}{ Wheat flour } & Springiness and PS & Springiness and T \\
\hline Takaragasa gold & $r=-0.92$ & $r=+0.95$ \\
Furian & $r=-0.93$ & $r=+0.94$ \\
Tokutakaragasa & $r=-0.80$ & $r=+0.81$ \\
Aokoma & $r=-0.93$ & $r=+0.91$ \\
\hline
\end{tabular}

no studies had yet proposed that the hydrophobicity of whole wheat flour was affected by storage. We therefore examined the rheological changes in hydrophobicity occurring in stored wheat flours using mixograph and RVA tests.

Mixograph and RVA tests of stored wheat flour Figure 2 indicates the mixograph profiles of "Aokoma" flours stored for 2, 4, 6, 8, 10 and 12 months at room temperature. Large swings of pen arm in the early stages of the mixograph profiles were observed when dough began to coil around the mixograph pins, and changed to lower 
constant swings in unstored wheat flour. However, dough made from flours stored for 6-10 months were increasingly difficult to coil around the pins, and it took longer for large swinging to begin, indicating that storage of wheat flour would change flour hydrophobicity and

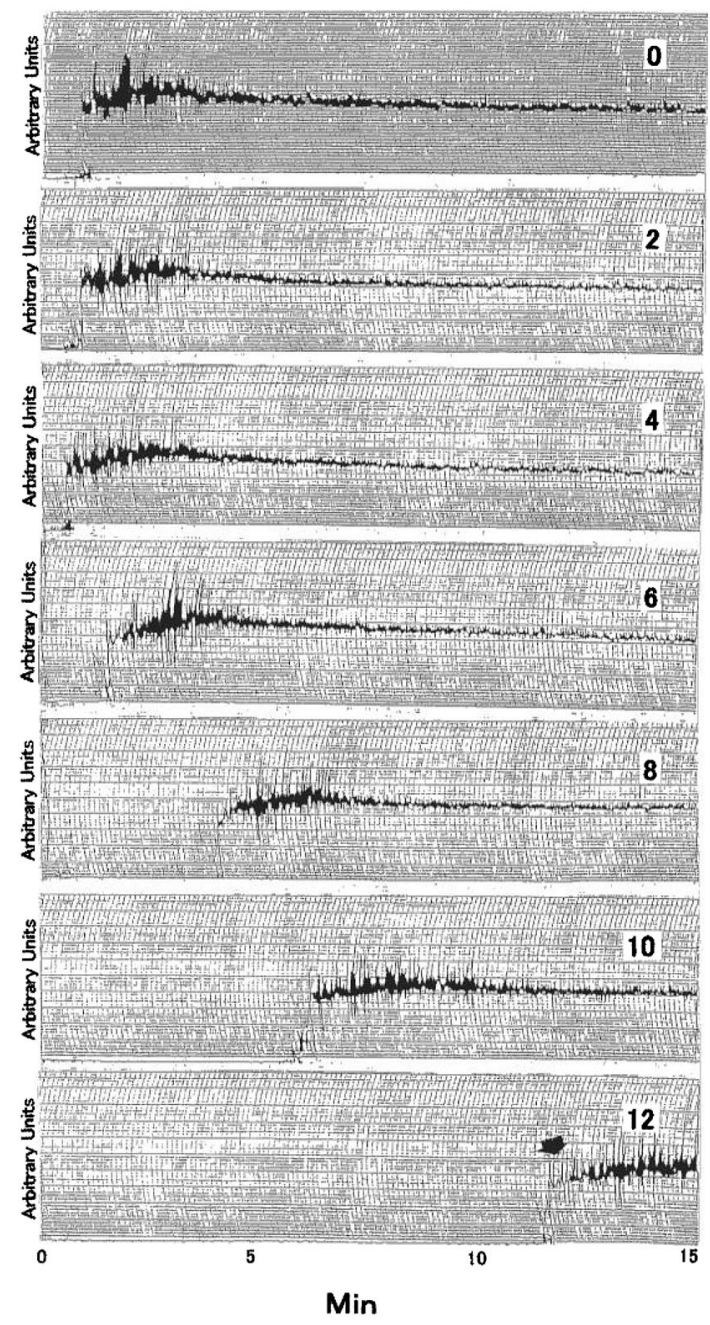

Fig. 2. Effect of storage at room temperature on "Aokoma" flour in mixograph profiles at 0, 2, 4, 6, 8, 10 and 12 months. that added water was not easily absorbed by the flour. Dough from flour stored for 12 months finally allowed large swings after 11 minutes (indicated in Fig. 2). It was reported by Ozawa and Seguchi (2006) that the hydrophobicity of dry heated wheat flours could be observed using a mixograph test. Seguchi et al. (1998) and Kusunose et al. (2002) also proposed that the hydrophobicity of wheat flour was caused by flour components such as starch granules. Other flours, "Takaragasa gold", "Furian" and "Tokutakaragasa", showed the same results (data were not shown here).

RVA profiles of "Aokoma” flour stored for 2, 4, 6, 8, 10 or 12 months at room temperature are shown in Fig. 3. Starch granules in unstored flour swelled separately in the RVA canister. In contrast, starch granules in stored flour which showed hydrophobicity (Seguchi, 1993) aggregated through protein and tailings fractions and swelled together, resulting in an increase in maximum viscosity from 571 (0 months) to 822 RVU (12 months) and a decrease in the pasting temperature from 94.4 ( 0 months) to $78.1^{\circ} \mathrm{C}$ (12 months); similar results were obtained for "Takaragasa gold", "Furian" and "Tokutakaragasa" flours. The results suggest that storage of wheat flours changes the properties of starch granules, leading to an increase in maximum viscosity of flour, and that variations in the pasting temperature are the result of interaction between the prime starch and tailings fractions.

\section{Conclusions}

It was found that storage of various protein-containing wheat flours "Takaragasa gold", "Furian”, “Tokutakaragasa", and "Aokoma" at room temperature led to an increase the springiness of pancakes made from these flours, as well as increases in the interaction between prime starch and tailings fractions. Mixograph profiles of wheat flours indicated that the storage of wheat flours induced strong hydrophobicity, and RVA profiles of stored and hydrophobic wheat flours indicated an increase in peak viscosities and a decrease in pasting temperatures.

Improvements in the springiness of pancakes made with stored wheat flour are thus considered to be caused by increases in semi-rigid gas cell structures composed of

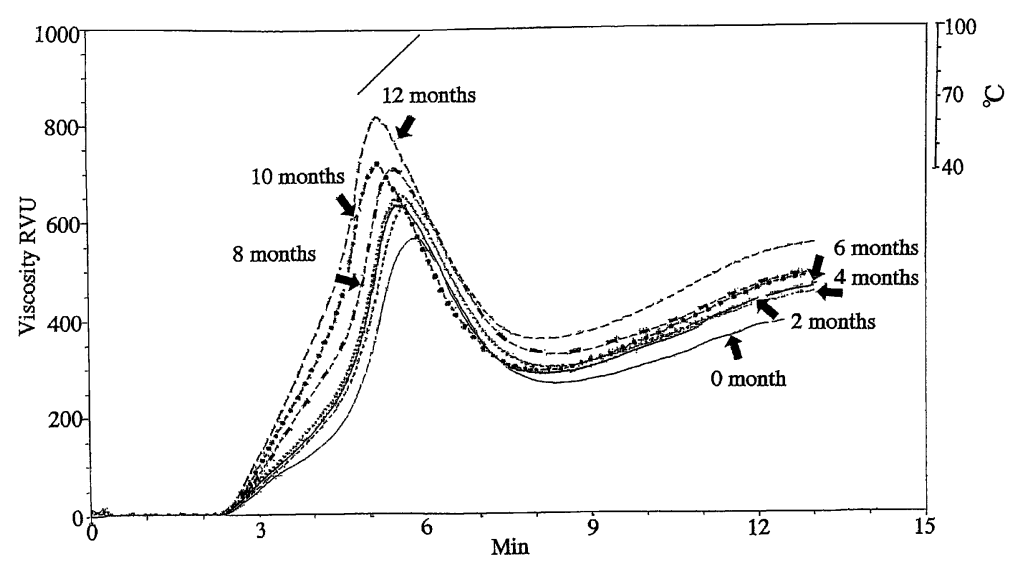

Fig. 3. Effect of storage at room temperature on "Aokoma" flour in RVA-profiles at 0, 2, 4, 6, 8, 10 and 12 months. 
hydrophobic flour components such as prime starch and tailings fractions.

\section{References}

American Association of Cereal Chemists. 2000. Approved Methods of the AACC, 10th Ed. Method 08-01 and Method 46-10. St. Paul, Minnesota USA.

Becker, H.A. and Sallans, H.R. 1956. A study of the relation between time, temperature, moisture content, and loaf volume by the bromate formula in the heat treatment of wheat and flour. Cereal Chem., 33: 245-265.

Hamer, R.J. and Hoseney, R.C. 1998. Interactions: The Keys to Cereal Quality. American Association of Cereal Chemists: St. Paul, Minnesota USA. p 95-130.

Kusunose, C., Noguchi, S., Yamagishi, T. and Seguchi, M. 2002. Binding of prime starch to tailings fraction by proteins in stored wheat flour. Food Hydrocolloids, 16: 73-77.
Ozawa, M. and Seguchi, M. 2006. Relationship between pancake springiness and interaction of wheat flour components caused by dry heating. Food Sci. Technol. Res., 12: 167-172.

Seguchi, M. and Matsuki, J. 1977. Studies on pan-cake baking. I. Effect of chlorination of flour on pan-cake qualities. Cereal Chem., 54: 287-299.

Seguchi, M. 1984. Oil-binding ability of heat-treated wheat starch. Cereal Chem., 61: 248-250.

Seguchi, M. 1990. Effect of heat-treatment of wheat flour on pancake springiness. J. Food Sci., 55: 784-785.

Seguchi, M. 1993. Effect of wheat flour aging on starch-granule surface proteins. Cereal Chem., 70: 362-364.

Seguchi, M., Hayashi, M., Kanenaga, K., Ishihara, C. and Noguchi, S. 1998. Springiness of pancake and its relation to binding of prime starch to tailings in stored wheat flour. Cereal Chem., 75: $37-42$. 